Association for Information Systems AIS Electronic Library (AISeL)

Wirtschaftsinformatik Proceedings 2003

Wirtschaftsinformatik

September 2003

\title{
Using Management Objectives to Specify Management Information Systems - A Contribution to MIS Success
}

Jörg Becker

WestfälischeWilhelms-Universität, becker@wi.uni-muenster.de

Alexander Dreiling

Westfälische Wilhelms-Universität, isaldr@wi.uni-muenster.de

Michael Ribbert

Westfälische Wilhelms-Universität

Follow this and additional works at: http://aisel.aisnet.org/wi2003

\section{Recommended Citation}

Becker, Jörg; Dreiling, Alexander; and Ribbert, Michael, "Using Management Objectives to Specify Management Information Systems - A Contribution to MIS Success" (2003). Wirtschaftsinformatik Proceedings 2003. 69.

http://aisel.aisnet.org/wi2003/69

This material is brought to you by the Wirtschaftsinformatik at AIS Electronic Library (AISeL). It has been accepted for inclusion in Wirtschaftsinformatik Proceedings 2003 by an authorized administrator of AIS Electronic Library (AISeL). For more information, please contact elibrary@aisnet.org. 
In: Uhr, Wolfgang, Esswein, Werner \& Schoop, Eric (Hg.) 2003. Wirtschaftsinformatik 2003: Medien - Märkte - Mobilität, 2 Bde. Heidelberg: Physica-Verlag

ISBN: 3-7908-0111-9 (Band 1)

ISBN: 3-7908-0116-X (Band 2)

(C) Physica-Verlag Heidelberg 2003 


\title{
Using Management Objectives to Specify Management Information Systems - A Contribution to MIS Success ${ }^{1}$
}

\author{
Jörg Becker, Alexander Dreiling, Michael Ribbert \\ Westfälische Wilhelms-Universität
}

\begin{abstract}
Data warehouse projects, today, are in an ambivalent situation. On the one hand, data warehouses are critical for a company's success and various methodological and technological tools are sophisticatedly developed to implement them. On the other hand, a significant amount of data warehouse projects fails due to non-technical reasons such as insufficient management support or incorporative employees. But management support and user participation can be increased dramatically with specification methods that are understandable to these user groups. This paper aims at overcoming possible non-technical failure reasons by introducing a user-adequate specification approach within the field of management information systems.
\end{abstract}

Key Words: Management Information Systems, Data Warehousing, Management Information Requirements, Meta Modeling, Corporate Planning

\section{Introduction}

Today, IT and IS projects are faced with an increased pressure from a business perspective. Ongoing discussions on the business value of IT $\left[\mathrm{HiBr} 96, \mathrm{Im}^{+} 01\right.$, $\mathrm{Mukh}^{+} 95$, SuWa01, Tam98] clearly point out that the risk awareness of such projects has changed. High costs and high overall failure rates of IS projects [Stan01] increase this risk awareness additionally. KEIL states that a significant number of IS projects (30-40\%) exceeding predefined time restrictions and allocated resources but never reaching their objective, will ultimately escalate and fail $\left[\right.$ Keil95, Keil $\left.{ }^{+} 00\right]$. The high failure rate, especially of complex IS projects, indicates that some so-called best practices for IS development are inadequate. There is a continually increasing need for methodological approaches that are theoretically sufficiently well-founded to handle complex IS projects [ $\left.\mathrm{Jian}^{+} 01\right]$.

\footnotetext{
This work has been funded by the German Federal Ministry of Education and Research (Bundesministerium für Bildung und Forschung), record no. 01HW0196.
} 
On the other hand, IT and IS have lately been more often recognized as a vital backbone of an organization, instead of a simple business support tool $[\mathrm{HeVe} 99$, LiCh01, Venk94]. Furthermore, IT and IS play important roles in creating competitive advantages, making IT and IS essential for companies acting on markets with a strong competition [JoVi88].

From an IS perspective, a broad variety of methods, architectures, and solutions aim at supporting the IS development process [Hirs ${ }^{+} 95$, LeTr00]. As an example, data warehouse architectures are well understood and data warehouse projects have been conducted quite over a long period. Nevertheless, many data warehouse projects fail for several reasons [Vass00]. Some reasons for failure of data warehouse projects can hardly be influenced, such as bad source data quality. Other reasons can be influenced during the project, such as the involvement of management as targeted users of the system or management support both of which contribute to system quality and system success [WiWa01]. Management support for the project is one of the essential factors for organizational implementation success and user participation significantly contributes to project implementation success [WiWa01]. Both organizational implementation success and project implementation success contribute to system quality and system success [WiWa01].

As management support and user participation are major success factors, management, management supporters, and intended users, need to be explicitly addressed during a data warehouse project. If the management is convinced of and satisfied with the future data warehouse environment, it will more willingly support the project. If, furthermore, intended users are involved in the development process, they will be more willingly using the system.

In this paper we address the enhanced involvement of both management and users during a management information system project (based on a data warehouse architecture). Managers usually have perspectives or goals which they pursue during their work. We will show how operationally specified objectives can help to retrieve further information from managers, that are essential for the specification of an MIS. Additionally, we will show how operationally specified objectives can be decomposed into different components. These components can be used for creating data warehouse structures which enable the management to monitor to which degree an objective has been accomplished. In order to do so, we reflect the relevant literature in the next section. In section 3 we will introduce a meta model that allows for structuring operational objectives. We will embed this meta model into previous work on the specification language of the MetaMIS approach, which aims at specifying managerial views. Section 4 contains an elaborate example case using our introduced method. Finally, in section 5 the findings are summarized and future prospects discussed. 


\section{Related Work}

\subsection{Data Warehousing}

From a management perspective, data warehouses provide an accepted architecture for the development of decision support systems. A data warehouse stores materialized views on relational representations of business processes, in order to provide relevant information for managerial decisions [Inmo96, InHa94, Inmo+97]. The warehouse is the central layer of a theoretically ideal three-layer architecture connecting online transaction processing (OLTP) systems and components enabling online analytical processing (OLAP) [BeHo98, ChDa97]. Contributions within the field of data warehousing range from technical discussions of databases and algorithms enabling OLAP functionality [Agra+96, CaTo01, Codd+93, Coll96, GyLa97, VaSe99] to studies on the information search behavior of managers [Borg $\left.{ }^{+} 98\right]$ and to articles concentrating on methodologies for information systems development [Golf $\left.{ }^{+} 98\right]$. Recently, methodological contributions $\left[\mathrm{Jark}^{+} 99\right.$, Jark $\left.{ }^{+} 00\right]$ propose a quality-oriented framework for data warehouse development. OLAP supports adequate navigation for the purpose of managerial analysis, through so-called multi-dimensional information spaces. Business process data from OLTP systems are the source of OLAP analyses. Typically, the integration of OLTP systems and a data warehouse is based on tools performing $e x$ traction, transformation, and loading tasks (ETL) on the source data [Inmo96, Wido95].

\subsection{Meta Modeling}

Meta models can be used to create meta data schemas of data warehouses [Holt99, Holt03]. Whereas a model describes a real-world object itself, a meta model is usually referred to as a model of a language that describes this real-world object [Holt00, Niss ${ }^{+} 96$, Stra96]. Thus, model and meta model are related to the same real world object. This kind of meta model is referred to as a language based meta model [Stra96]. HoLTEN depicts the interdependencies of meta level, type level, and instance level on three layers [Holt00]. It is stated, that a model M1 of a realworld object is described in a language L1, which itself is described in a model M2 (meta model of the real world object). According to MORRIS a language consists of a set of interrelated signs [Morr71, p.24]. Semiotic as a science states facts about signs and is divided into three subordinate braches, syntactics, semantics, and pragmatics [Morr71, p. 23]. Syntactics, to which we refer again using the more common term of syntax, deals with the "relations of signs to one another" [Morr71, p. 28]. Semantics "deals with the relation of signs to their designata and so to the objects which they may or do donate" [Morr71, p. 35]. Thus, it addresses the meaning of symbols. Finally, pragmatics is "the science of the relation of signs 
to their interpreters" [Morr71, p. 43]. It addresses the explanation of signs, which is imperative because misunderstandings would be unavoidable if different users of one language had different concepts of one sign in mind. Each of these aspects can be modeled, which adds the meta level above the type level. Together, the syntactical model, semantical model, and pragmatical model specify the languagebased meta model for the real world-object as shown in Figure 1.

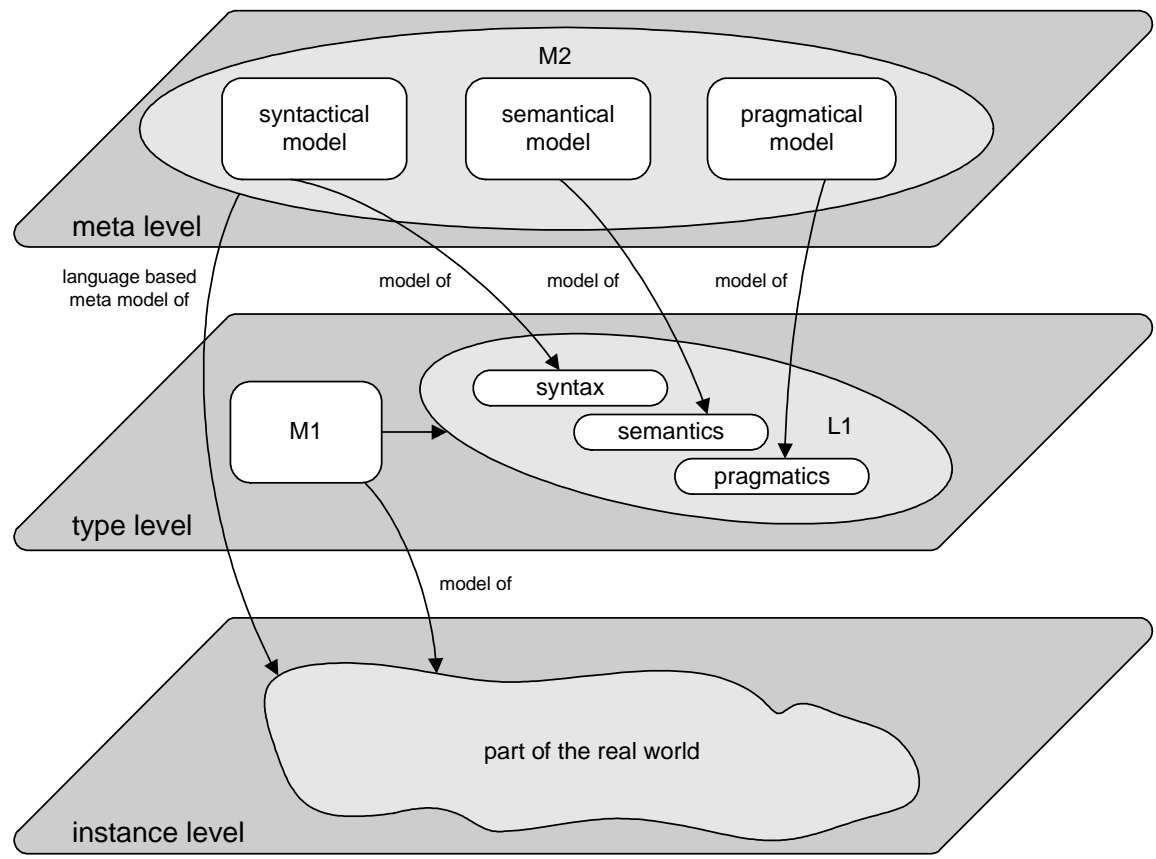

Figure 1: Arrangement of Models and Meta Models on Language Abstraction Levels (based on Holten 2000, p. 142)

\subsection{Specification of Management Information Systems}

Supporting the development process of a management information system environment the MetaMIS approach has been developed using meta models $\left[\operatorname{Beck}^{+} 03\right.$, Beck $^{+}$02, Holt00, Holt03, Holt ${ }^{+}$02] It aims at closing the communication gap between business departments and the IT department. A successful data warehouse project is characterized by a resulting management information system environment, which exactly meets the business requirements and works efficiently from a technical point of view. Therefore, the MetaMIS approach consists of a nontechnical language, a representation formalism and guidelines for modeling information spaces. The information behind MetaMIS models can be used to create logical data warehouse or data mart schemes. 
MetaMIS commences with the definition of Dimensions which consist of hierarchically-ordered Dimension Objects, e.g., products, customers, points in time, or customer sales representatives. Based on the enterprise theory of RIEBEL [Rieb79], dimension objects can be understood as entities subject to managerial analysis. In order to prevent information overflow, so-called Dimension Scopes need to be defined as subsets of existing dimensions (dimension object hierarchies) for different managerial activities. Dimension Scope Combinations comprise dimension scopes, creating navigation spaces for managerial analysis. Dimension scope combinations define a space of multi-dimensional objects (Reference Objects).

Aspects (either quantitative or qualitative) are assigned to these reference objects. Ratios (quantitative aspects) like "gross margin" define dynamic aspects of business objects and have clearly specified meanings. Their calculation is defined by algebraic expressions (e.g. "profit = contribution margin - fixed costs"). Qualitative aspects can be used, if business facts are measured by categorical values, such as efficiency or quality [Beck $\left.{ }^{+} 03\right]$. Aspects are organized into Aspect Systems which are structured hierarchically according to an aspect's importance for a managerial analysis. A drill-down logic is implied for aspect systems, which is to be separated especially from an algebraic definition of ratios. Aspect systems are assigned to dimension scope combinations (navigation spaces), in order to create Business Facts, such as the number of products sold in a certain region by a specific customer sales representative or the turnover achieved with one customer.

Dimension scope combinations and aspect systems are combined into an Information Object. Thus, it is a relation between a set of reference objects and a set of aspects with the element types being business facts. The MIS meta model underlying the MetaMIS approach is shown in Appendix A.

\section{Meta-Model-Based Approach to Management Information Requirements Specification}

\subsection{Objectives from a Business Perspective}

Effective and efficient MIS are designed to assist managers in making better decisions [ToBe99]. In order to implement such a system several IS requirements have to be met. From a business perspective, which we will focus on, the specification of management information requirements is essential to build an effective MIS. The designer of an MIS needs to know which objectives the MIS needs to support, information that only managers or management supporters can provide. Following, e.g., the MetaMIS approach, relevant dimensions, dimension groupings, aspects, or information objects have to be identified. Unfortunately, this is a non- 
trivial problem [Holt99]. Assisting this specification, we will show how managers' information requirements can be derived from corporate objectives.

We define operational corporate objectives by structuring the set of all objectives hierarchically. The different hierarchical levels can be represented as a pyramid, where the degree of measurability increases towards the bottom [Stei69]. Three different hierarchical levels build the top of the pyramid. They serve as a strategy, general condition or guideline for further planning and defining operational objectives:

- business mission specifies services and/or products produced within the firm [Meffoo],

- corporate identity specifies the appearance of the company to its stakeholders [Birk+93],

- policies and practices focus on the behavior towards customers, employees, environment, and earnings [Anso $\left.{ }^{+} 90\right]$

A major difficulty of business strategies is their non-operational character. Operational objectives are defined by a certain measure, level, time frame, and reference [Adam96]. Objectives need to be defined operationally in order to be manageable [LaKi74]. Usually, business strategies are not measurable. Nonetheless, operational effectiveness requires the definition of operational objectives. In order to align business strategy and operational effectiveness, the business strategy needs to be broken down into operational objectives in several steps. In the words of Porter "the essence of strategy is in the activities" [Port96], which means that operational objectives enable management to do the right things (defined by the business strategy) right (by derived operational objectives).

Following a strategy, general condition or guideline, the company can derive operational objectives. Operational objectives are:

- general goals, specifying aggregated operational objectives. General goals can be seen as benchmarks, helping managers from different organizational units to specify their objectives. General goals are, e.g., revenues or costs on a corporate level [Kups79],

- organizational unit goals, specifying the general goals on an organizational unit level. Thus, they vary from unit to unit. Examples are, e.g., production cost of the production department, revenues achieved by the sales department [Meffoo],

- business unit goals, specifying the organizational unit goals by breaking them down to the business unit level. For example, the revenues achieved by the sales department are split by market segments.

- marketing-mix-based goals, splitting up the business unit goals to the further partial goals such as price, promotion, place, and product. E.g., revenues of the 
sales department of market segment "Personal Computers" are sub-divided to partial goals concerning prices, promotions, distribution, and product design.

In contrast to general corporate objectives, detailed operational objectives can be managed. By breaking down corporate objectives into detailed operational objectives, managers are enabled with managing their area of competence. Operational objectives can be used to create plan-scenarios, which later can be used to control developments of a company.

Objective systems, especially large ones, face a major problem: they are usually inconsistent, which means that achieving one objective, inevitably leads to the failure of another. The inherent problem, as to how strategies are formed in organizations, is targeted by major research projects in the management research community [Grah71, Anso65, Barb02, Barn38, Gran64, Minz73]. However, we do not aim to support the definition of consistent objective systems. In fact, we assume that inconsistencies can be overcome by the approaches presented in the literature. We do support the monitoring of given objectives by comparing them to actual business developments.

The Balanced Scorecard is another approach that breaks down general business objectives to operational ones [KaNo92]. The BSC is a top down approach that provides managers with a comprehensive framework, translating a company's strategic objectives into a coherent set of performance measures [KaNo93]. Four different perspectives are provided. Information about traditional financial measures are enhanced by measures of performance for customers, internal processes, and innovation and improvement activities [KaNo00]. Thus, the BSC enables to balance between external measures like income or revenues and internal measures like product development and learning [KaNo93]. Furthermore, the BSC shows cause-and-effects links, which avoid trade-offs among different success factors.

\subsection{Construction of the Meta Model}

Having introduced the business background, we are now able to develop a meta model to assist the management information requirements specification. Referring to the related work in section 2.2 we will construct a syntactical meta model. A pragmatical foundation can be achieved by an approach, where meta model constructs are explained in a user adequate way. To accomplish the task of aligning the understanding of certain meta model constructs by different users, tables can be used as presented in [Holt03].

First, we introduce the construct Objective. Objectives can be organized hierarchically in more than one hierarchy which technically leads to an Objective Structure as a relationship type connecting Objective with itself. According to the relevant introduced literature, objectives can be categorized into different sub-objectives. This leads to several possible specializations. As introduced in the last section, one 
way to specialize Objective is unequivocally and total into Strategy, General Conditions and Guidelines and Operational Objective. Strategy, General Conditions and Guidelines can be further specialized into the entity types Business Mission, Corporate Mission, and Policy and Practice. Operational Objectives may be a General Goal, Organizational Unit Goal, Business Unit Goal, and MarketingMix-Based Goal. Another possibility to categorize Objective is the more commonly used distinction between Strategic Objective, Tactical Objective, and Operative Objective. The introduced specializations cannot be seen as an exhaustive list of possibilities. Other specializations may exist beyond the introduced ones and depending on the modeling purpose they can be specified.

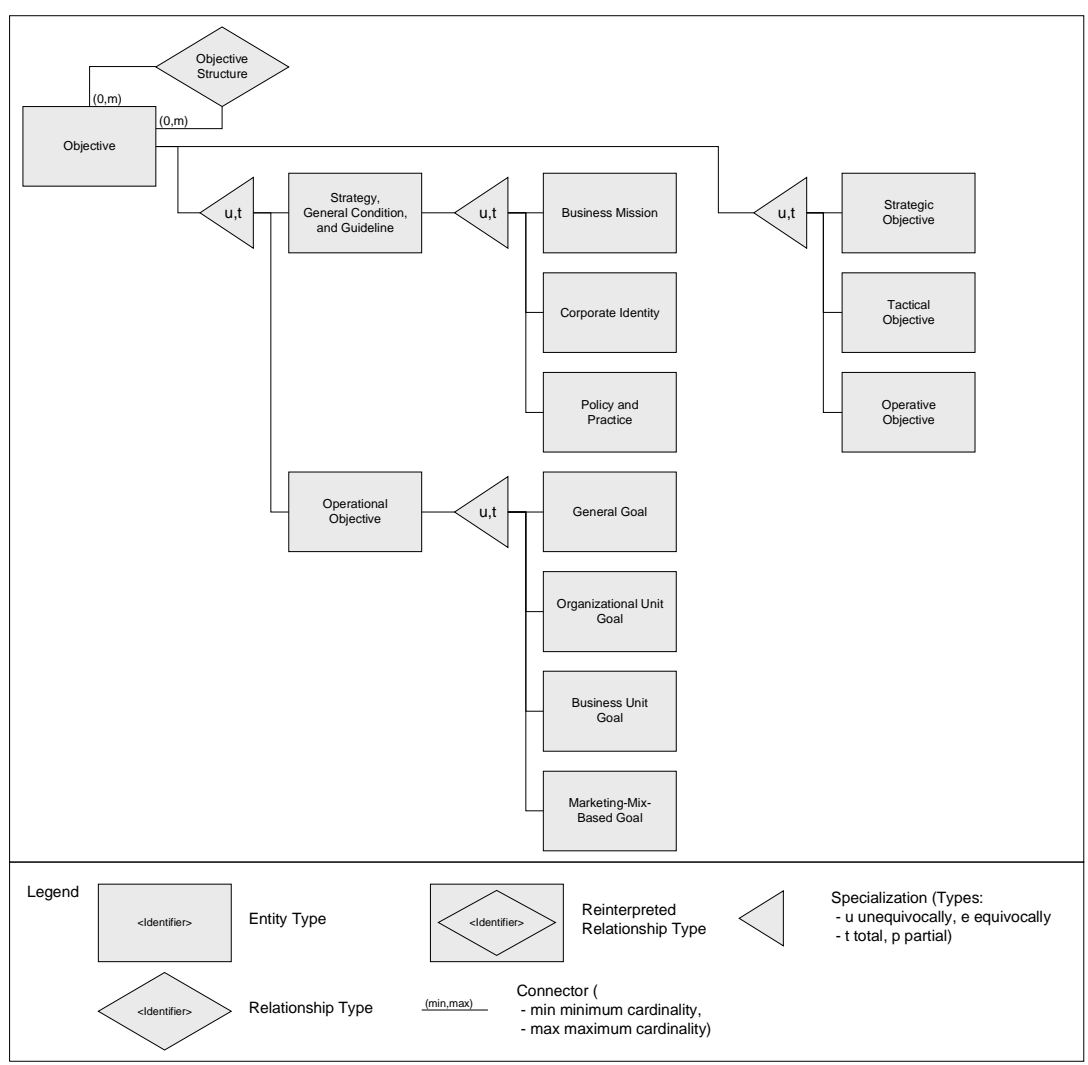

Figure 2: Specializations of Objective Including Objective Structure (Source: $\left[\mathrm{Beck}^{+} 03\right]$ )

As we explained above, objectives have to be specified operational to create planscenarios or to be used for controlling purposes. Operational objectives are defined by a certain measure, timeframe, reference, and level. To measure an objective, we introduce the construct Objective Measure. Different objectives may have different objective measures. Financial operational objectives, for instance, are measured quantitatively. For this purpose we need the modeling construct Quanti- 
tative Aspect (Ratio). Entities of this type belong to the class of interval or ratio measures [Adam96, HiKa02, Holt99]. Synonyms for the term ratio found in the management accounting literature are operating ratio, operating figure or measure of performance. The entire DuPont-Pyramid with its main ratio "return on investment" can be expressed based on algebraic expressions. Quantitative aspects can be used further for algebraic calculations. The construct Qualitative Aspect belongs to the class of nominal or ordinal measures. Examples of qualitative aspects are customer or employee satisfaction. For nominal and ordinal measures only a subset of further calculations is meaningful, such as aggregation operations.

Operational objectives need a timeframe and a reference. Each objective must have a certain space of time in which the objective has to be reached. E.g., the growth rate of revenues of a certain product must be defined for a certain period of time, for example one year. Besides a timeframe, operational objectives consist of another mandatory component, a reference. Every objective must refer to, e.g., a product, product group, service, or service group. Further objective references may be customers, management units, and others. The construct Reference Object combines timeframe and objective reference as requirements for operational objectives.

The last requirement for operational objectives is the definition of the Objective Level. The objective level combines the objective measure with a reference object. Having defined the objective measure, e.g., production efficiency and a reference object such as 'assembly line 42 , factory 37 , next year' we have to value the planned production efficiency of assembly line 42 in factory 37 within the next year to, e.g., level 9 (the example is introduced in more detail in Section 4). The meta model consisting of the constructs introduced above and their relationships is shown in Figure 3. 


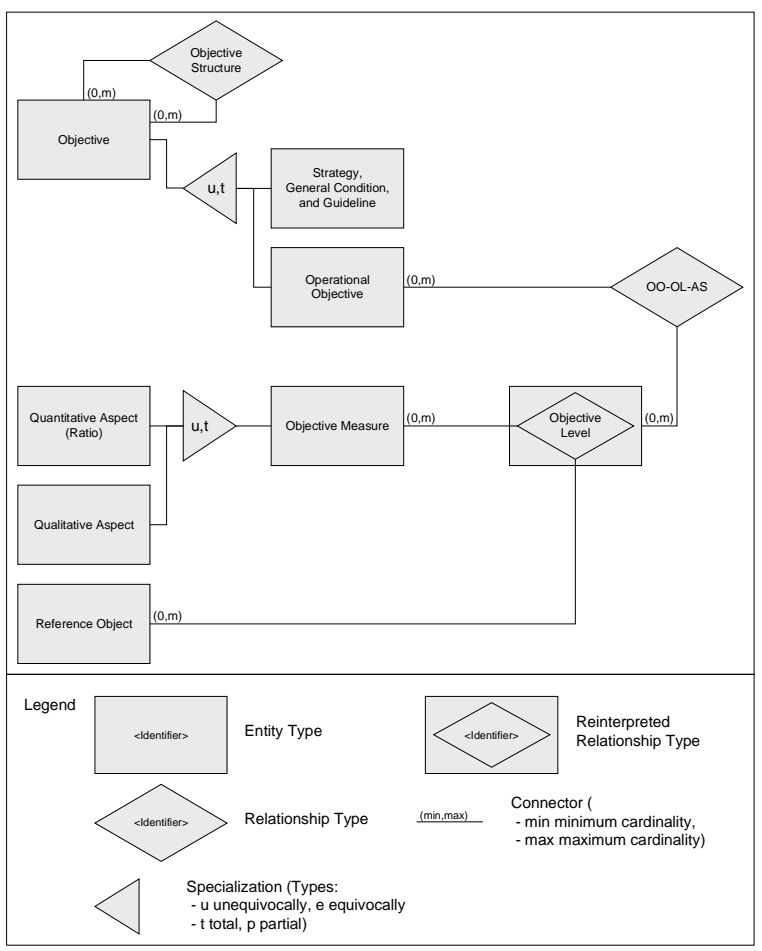

Figure 3: Objective Meta Model (Source: $\left[\mathrm{Beck}^{+} 03\right]$ )

By structuring operational objectives as described above, we gain several advantages. First, the meta model shown in Figure 3 can be integrated into the MetaMIS approach because it already features the constructs reference object and aspect $\left[\mathrm{Beck}^{+} 03\right.$, Holt03, Holt ${ }^{+}$02] (compare to Figure 4). Integrating our meta model into MetaMIS enables us to further use the methodology proposed by it, which includes deriving data warehouse structures from the specifications [Holt ${ }^{+} 02$ ]. Second, we are able to derive an initial set of information on the construction of navigation spaces for later analyses of the management. As shown in the next section, operational objectives can be decomposed to parts of objective references, time frames, and objective levels. The decomposed objective references will be transformed to dimension objects which later will constitute dimensions. 


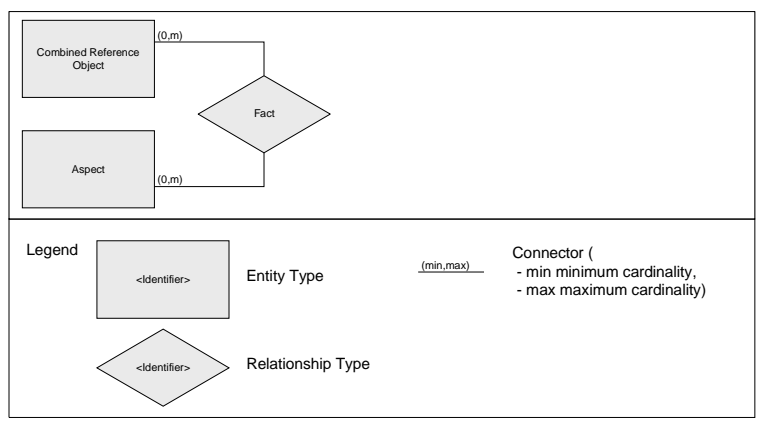

Figure 4: Fact-Segment of MIS Meta Model

\section{Example MIS Specification Case}

After having discussed business objectives and a possible objective meta model we will now use an example case to demonstrate, how objectives can be used to derive MIS specifications. Furthermore, we will show how objectives can be transformed into plan scenarios that fit into these data warehouse structures and allow for comparing planned scenarios with actual business developments.

\subsection{Operational Production Objectives}

Our example aims at enhancing the efficiency of a production assembly line. A company has defined efficiency levels beginning at zero (lowest level) up to ten (highest level). For a running assembly line the operational objective is the one already introduced in the last section:

- Objective Production Efficiency Enhancement: Increase production efficiency at assembly line 42 in factory 37 from level 8 to level 9 during the next year

The objective's time frame is next year, and the objective's reference is assembly line 42 in factory 37. The time frame combined with the reference constitutes the reference object. Efficiency is qualitative measure which is a Category (zero to ten) as well as a calculated ratio. To calculate the efficiency level three subobjectives need to be defined:

- Objective Rejection Rate Reduction: Decrease rejection rate of product group A products at assembly line 42 in factory 37 from four to two percent within the next year, without increasing the rejection rate of other product group's products assembled at this line 
- Objective Industrial Injury Rate Reduction: Decrease industrial injury rate of workers at assembly line 42 in factory 37 from 0.7 injuries per week to 0.3 injuries per week within the next year

- Objective Lead Time Reduction: Achieve an average lead time reduction during production of a single product group A product at assembly line 42 in factory 37 from 256 minutes to 240 minutes within the next year

We are now able to determine the relevant components of the introduced operational objectives as shown in Table 1.

\begin{tabular}{|c|c|c|c|c|c|}
\hline Objective & Sub-Objective & Reference & Time Frame & Measure & Level \\
\hline \multicolumn{2}{|c|}{ production efficiency enhancement } & assembly line 42 , factory 37 & next year & efficiency & 9 \\
\hline & rejection rate reduction & $\begin{array}{l}\text { product group A products, } \\
\text { assembly line } 42 \text {, factory } 37\end{array}$ & next year & rejection rate & 2 percent \\
\hline & $\begin{array}{l}\text { industrial injury rate } \\
\text { reduction }\end{array}$ & $\begin{array}{l}\text { workers, assembly line } 42 \text {, } \\
\text { factory } 37\end{array}$ & next year & industrial injury rate & 0.3 injuries per week \\
\hline & lead time reduction & $\begin{array}{l}\text { single products of group A, } \\
\text { assembly line } 42 \text {, factory } 37\end{array}$ & next year & average lead time & 240 minutes \\
\hline
\end{tabular}

Table 1: Operational Objective Components

Again, reference and time frame combined, constitute the reference object of all objectives as time is also a reference.

\subsection{Creating a Conceptual MIS Model - Navigation Space}

Having defined operational objectives and structured them hierarchically, we are now able to create a conceptual MIS model. Within an MIS environment we need to define dimensions which consist of hierarchically structured dimension objects [Holt03, Holt ${ }^{+}$02]. For that, as a first step, the initial set of objective references taken from the definitions of operational objectives can be decomposed. The objects of the Reference-column in Table 1 represent such decomposed objective references, which will be redefined as dimension objects and structured hierarchically. They thus form the basic structure of what will be a dimension. This process is complex creative work. Even so, without a methodological approach such as the one presented here, no assistance with this process would be available.

Questioning managers on basis of the specified operational objectives is imperative for deriving further insights into the structures of the information systems supporting managerial analysis. Our example objective Rejection Rate Reduction states that rejection rates of other product group's products must not increase. This inevitably leads to the question as to which other product groups should be considered for managerial analysis. The plan scenario that needs to be set up will include the objective level of product group A, which needs to be decreased according to the objective. Furthermore, it includes the objective levels for all other product groups which must not exceed the respective levels of the previous year. 
The identification of dimensions can be assisted by answering the question of whether the elements of operational objective references are structured in an n:m relationship or in a 1:m relationship. The first case implies the modeling of two dimensions (because dimensions are hierarchical constructs of dimensions objects) whereas in the latter case, only one dimension is modeled. This decision needs to be made carefully. It needs to be identified whether this 1:m relationship occurs only temporarily, just as objective references of operational objectives, or generally. If it occurs generally, it is imperative to know, if the relationship might be changed by an ongoing business strategy. As mentioned above, identifying dimensions is a complex process which directly influences data warehouse structures. It can be seen as a strategic decision during the MIS specification process.

In our example objectives from Table 1 there are five types of fundamentally different entities, assembly lines, factories, workers, products and times. The first four entity types are derived from the objectives' references. The objectives' time frames will be transformed to dimension objects and added to a combined reference object, because technically there is no difference between an objective's reference and an objective's time frame. Now, does an assembly line always belong to one factory or can it be spread over more than one factory? Is it possible that a factory runs more than one assembly line? Do workers work in one factory (at one assembly line) or are they allocated among more factories (assembly lines)? Questions like these are possible because operational objectives have been specified and structured according the proposed method. And they need to be answered by responsible personnel to specify the MIS. Implying n:m relationships between assembly lines, factories, workers, products, and time, we would construct five dimensions.

After the identification of dimensions their basic structure consisting of dimension objects that have been derived from operational objectives needs to be completed. Other dimension objects that will further be necessary to answer the managers' questions need to be added. Basically, this means that all relevant products of all product groups (product group A and all others that resulted from the answer to the question derived from the operational objective Rejection Rate Reduction) are added to the product dimension. In this case the product dimension would be extended by a hierarchy level containing all products.

Basing on the leaves of dimensions we can subsume a set of dimensions to a dimension grouping in case the set of leaves of these dimensions is equal [Holt03, Holt $\left.^{+} 02\right]$. This might occur if, e.g., one operational objective's time frame was a month and another one's Mondays (e.g., monthly average lead times vs. Monday production rejection rate). Certainly, in this case days would be at the lowest level, but in one dimension they would be aggregated to weekdays, whereas in another they would be aggregated to months. The existence of dimension groupings, again, influences the data warehouses design. Dimension groupings will later be represented by a column in the fact table, dimensions as hierarchies in lookup tables. 
After having specified complete dimensions and dimension groupings, we need to define dimension scopes for managerial activities [Holt03, Holt ${ }^{+} 02$ ]. As dimensions may grow large, certainly not every manager needs every piece of information. On the one hand this addresses the problem of information overflow. On the other hand it might not be wanted that managers can have a look at different management units. Dimension scope combinations combine managerial activityspecific dimension scopes and create navigation spaces [Holt03, Holt ${ }^{+} 02$ ].

\subsection{Creating a Conceptual MIS Model - Plan Scenarios}

As the last step, operational objectives are extended by the reference component version. Version is a dimension consisting of the dimension objects actual, and several plan-dimension objects. Plan dimension objects could be plan optimistic, plan pessimistic, or various other versions. This extension completes the requirements definition by transforming operational objectives into plan scenarios. Objective measures become either qualitative or quantitative aspects depending on the nature of their values. Measures itself will be assigned to reference objects of navigation spaces allowing for easy plan variance analyses by comparing plan with actual facts.

In order to transform operational objectives into plan scenarios, we need to assign a value of the dimension version, e.g., plan version 1 to the combined reference object. This enables us to monitor, whether the objective has been reached or not. The example objective increase production efficiency at assembly line 42 in factory 37 from level 8 to level 9 during the next year would be decomposed and transformed into the reference object assembly line 42, factory 37, and next year. A plan version (e.g. plan optimistic) will be added to the reference object. This reference object can be assigned to the objective measure production efficiency, which will be a qualitative aspect. The plan fact would be assembly line 42, factory 37, next year, plan optimistic assigned to the aspect production efficiency with a value of level 9. Later, it can be used in a plan variance analysis with the fact assembly line 42, factory 37, next year, actual assigned to the aspect production efficiency with the value actually achieved in the analyzed year.

\section{Conclusions and Outlook}

According to WIXOM \& WATSON, implementation success within data warehouse projects can be categorized into organizational, project, and technical implementation success [WiWa01]. Management Support has been determined to be one of the most influencing variables for organizational implementation success [WiWa01]. We targeted management support by providing a method for structuring operational management objectives and further transforming them into data 
warehouse structures. Furthermore, we showed how operationally specified management objectives may be decomposed for structuring purposes and how these components may be used to further question the management. Thus, our specification method is business-driven.

User participation has been determined as a success factor for project implementation success [WiWa01]. We targeted user participation as management support, because the management is the core user group of a management information system.

Other influencing success factors for data warehouse development projects are resources (money, time, and people required to complete the project successfully), team skills (both technical and interpersonal skills of team members), source systems (quality of operational systems), and the technological basis (IT and IS involved) [WiWa01]. These factors cannot be influenced by a modeling approach and thus they are not addressed by our work.

Our future research will concentrate on improving our method. We intend to practically validate the method in some business cases. Furthermore, we aim at supporting the data warehouse projects success factors that have not been addressed in this work.

\section{References}

[Adam96] Adam, D.: Planung und Entscheidung. Gabler: 4th edition. Wiesbaden, Germany, 1996.

[Agra ${ }^{+}$96] Agarwal, S. et al.: On the computation of multidimensional aggregates. In: Proceedings of the 22nd International Conference on Very Large Data Bases, San Francisco, CA, 1996, S. 506-521.

[Grah71] Allison, G. T.: Essence of Decisions. Little, Brown. Boston, MA, USA, 1971.

[Anso65] Ansoff, H. I.: Corporate Strategy. McGraw-Hill. New York, NY, USA, 1965.

[Anso ${ }^{+}$90] Ansoff, H. I. et al.: Implanting strategic management. Prentice-Hall: 2nd edition. London, 1990.

[Barb02] Barbuto Jr., J. E.: How is Strategy Formed in Organizations? A MultiDisciplinary Taxonomy of Strategy-Making Approaches. Journal of Behavioral and Applied Management 3(1), 2002: S. 64-73.

[Barn38] Barnard, C. I.: The Functions of the Executive. Harvard University Press. Cambridge, MA, USA, 1938.

[Beck ${ }^{+}$03] Becker, J. et al.: Specifying Information Systems for Business Process Integration - A Management Perspective. Information Systems and eBusiness Management 1(2), 2003. 
[Beck ${ }^{+}$03] Becker, J.; Dreiling, A.; Ribbert, M.: Meta-Model-based Approaches to Information Systems Engineering. In: Proceedings of the 2003 Information Resources Management Association Conference, Philadelphia, PA, USA, 2003.

[BeHo98] Becker, J.; Holten, R.: Fachkonzeptuelle Spezifikation von Führungsinformationssystemen. Wirtschaftsinformatik 40(6), 1998: S. 483-492 [in German].

[Beck ${ }^{+}$2] Becker, J.; Ribbert, M.; Dreiling, A.: Contribution of Meta Models to Systems Engineering - A CRM Example. In: Proceedings of the Information Systems Foundation: Building the Theoretical Base, Canberra, ACT, Australia, 2002, S. 191-204.

[Birk $\left.{ }^{+} 93\right]$ Birkigt, K.; Stadler, M. M.; Funck, H. J.: Corporate Identity: Grundlagen, Funktionen, Fallbeispiele. Verlag Moderne Industrie: 5th edition. Landsberg am Lech, 1993.

[Borg $\left.{ }^{+} 98\right]$ Borgman, H. P.: Manager`s information search behaviour using Management Support Systems. Wirtschaftsinformatik 40(6), 1998: S. 527-535.

[CaTo01] Cabibbo, L.; Torlone, R.: An Architecture for Data Warehousing Supporting Data Independence and Interoperability. International Journal of Cooperative Information Systems 10(3), 2001: S. 377-397.

[ChDa97] Chaudhuri, S.; Dayal, U.: An overview of data warehousing and olap technology. ACM SIGMOD Record 26(1), 1997: S. 65-74.

[Codd $\left.{ }^{+} 93\right]$ Codd, E. F.; Codd, S. B.; Salley, C. T.: Providing olap (On-Line Analytical Processing) to User Analysts: An IT Mandate. White Paper, E. F. Codd \& Associates, 1993.

[Col196] Colliat, G.: OLAP, relational, and multidimensional database systems. ACM SIGMOD Record 25(3), 1996: S. 64-69.

[Golf ${ }^{+}$98] Golfarelli, M.; Maio, D.; Rizzi, S.: The Dimensional Fact Model: A Conceptual Model for Data Warehouses. International Journal of Cooperative Information Systems 7(2 \& 3), 1998.

[Gran64] Granger, C. H.: The Hierarchy of Objectives. Harvard Business Review 42(MayJune), 1964: S. 63-74.

[GyLa97] Gyssens, M.; Lakshmanan, L. V. S.: A foundation for multi-dimensional databases. In: Proceedings of the International Conference on Very Large Data Bases, San Francisco, CA, 1997, S. 106-115.

[HeVe99] Henderson, J. C.; Venkatraman, N.: Strategic Alignment: Leveraging Information Technology for Transforming Organizations. IBM Systems Journal 38(2/3), 1999: S. 472-484.

[HiKa02] Hillbrand, C. A.; Karagiannis, D.: An Approach to Faciliate Complex Planning Issues by Means of Machine Learning Techniques Applied to Cybernetic Cause-andEffect Models. In: Proceedings of the SCI 2002 - 6th World Multiconference on Systemics Informatics and Cybernetics, Orlando, FL, USA, 2002.

[Hirs ${ }^{+}$95] Hirschheim, R.; Klein, H. K.; Lyytinen, K.: Information Systems Development and Data Modeling. Cambridge University Press. Cambridge, UK, 1995. 
[HiBr96] Hitt, L. M.; Brynjolfsson, E.: Productivity, Business Profitability, and Consumer Surplus: Three Different Measures of Information Technology Value. MIS Quarterly 20(2), 1996: S. 121-142.

[Holt99] Holten, R.: Entwicklung von Führungsinformationssystemen. Ein methodenorientierter Ansatz. Gabler. Wiesbaden, Germany, 1999.

[Holt00] Holten, R.: Framework and Method for Information Warehouse Development Processes. In: Proceedings of the Data Warehousing 2000 - Methoden, Anwendungen, Strategien, Heidelberg, Germany, 2000, S. 135-163.

[Holt03] Holten, R.: Specification of Management Views in Information Warehouse Projects. Accepted for publication in Information Systems 28, 2003.

[Holt ${ }^{+}$02] Holten, R.; Dreiling, A.; Schmid, B.: Management Report Engineering - A Swiss Re Business Case. In: Proceedings of the Data Warehousing 2002 Conference, 2002.

[Im+01] Im, K. S.; Dow, K. E.; Grover, V.: Research Report: A Reexamination of IT Investments and the Market Value of the Firm-An Event Study Methodology. Information Systems Research 12(1), 2001: S. 103-120.

[Inmo96] Inmon, W. H.: Building the Data Warehouse. Wiley: 2nd edition. New York, NY et al, 1996.

[InHa94] Inmon, W. H.; Hackathorn, R. D.: Using the Data Warehouse. Wiley. New York, NY et al, 1994.

[Inmo ${ }^{+}$97] Inmon, W. H.; Welch, J. D.; Glassey, K. L.: Managing the Data Warehouse. Wiley. New York, NY et al, 1997.

[Jark $\left.{ }^{+} 99\right]$ Jarke, M. et al.: Architecture and Quality in Data Warehouses. An extended Repository Approach. Information Systems 24(3), 1999: S. 229-253.

[Jark $\left.{ }^{+} 00\right]$ Jarke, M. et al.: Fundamentals of Data Warehouses. Berlin et al., 2000.

[Jian $\left.{ }^{+} 01\right]$ Jiang, J. J.; Klein, G.; Discenza, R.: Information System Success as Impacted by Risks and Development Strategies. IEEE Transactions on Engineering Management 48(1), 2001: S. 46-55.

[JoVi88] Johnston, H. R.; Vitale, M. R.: Creating Competitive Advantages with Interorganizational Information Systems. MIS Quarterly 12(2), 1988: S. 153-165.

[KaNo92] Kaplan, R. S.; Norton, D. P.: The Balanced Score Card. Measures that Drive Business Performance. Harvard Business Review 70(January-February), 1992: S. 7179.

[KaNo00] Kaplan, R. S.; Norton, D. P.: Having Trouble with Your Strategy? Then Map It. Harvard Business Review 78(September-October), 2000: S. 167-176.

[KaNo93] Kaplan, R. S.; Norton, D. P.: Putting the Balanced Scorecard to Work. Harvard Business Review 71(September-October), 1993: S. 134-142.

[Keil95] Keil, M.: Pulling the Plug: Software Project Management and the problem of Project Escalation. MIS Quarterly 19(4), 1995: S. 421-447. 
[Keil+00] Keil, M.; Mann, J.; Rai, A.: Why Software Projects Escalate: An Empirical Analysis and Test of Four Theoretical Models. MIS Quarterly 24(4), 2000: S. 631-664.

[Kups79] Kupsch, P.: Unternehmensziele. Gustav Fischer-Verlag. Stuttgart, New York, 1979.

[LaKi74] Latham, G. P.; Kinne, S. B.: Improving Job Performance through Training in Goal Setting. Journal of Applied Psychology 59, 1974: S. 187-191.

[LeTr00] Lee, J.; Truex, D. P.: Exploring the impact of formal training in ISD methods on the cognitive structure of novice information systems developers. Information Systems Journal 10, 2000: S. 347-367.

[LiCh01] Li, E. Y.; Chen, H.-G.: Output-driven information system planning: a case study. Information \& Management 2001(38), 2001: S. 185-199.

[Meff00] Meffert, H.: Marketing. Grundlagen marktorientierter Unternehmensführung. Konzepte - Instrumente - Praxisbeispiele. Gabler. Wiesbaden, Germany, 2000.

[Minz73] Mintzberg, H.: Strategy Making in Three Modes. California Management Review 16(2), 1973: S. 44-53.

[Morr71] Morris, C.: Writings on the General Theory of Signs. Mouton. The Hague, the Netherlands, 1971.

[Mukh+95] Mukhopadhyay, T.; Kekre, S.; Kalathur, S.: Business Value of Information Technology: A Study of Electronic Data Interchange. MIS Quarterly 19(2), 1995: S. 137-156.

[Niss+96] Nissen, H. W. et al.: Managing Multiple Requirements Perspectives with Metamodels. IEEE Software 13(3), 1996: S. 37-48.

[Port96] Porter, M. E.: What is Strategy? Harvard Business Review 74(NovemberDecember), 1996: S. 61-78.

[Rieb79] Riebel, P.: Gestaltungsprobleme einer zweckneutralen Grundrechnung. Zeitschrift für betriebswirtschaftliche Forschung 31, 1979: S. 863-893.

[Stan01] Standish Group International, I.: Extreme CHAOS. Research report, ordering information available at www.standishgroup.com, 2001.

[Stei69] Steiner, G. A.: Top Management Planning. Macmillan: 13th edition. New York, NY, USA, 1969.

[Stra96] Strahringer, S.: Metamodellierung als Instrument des Methodenvergleichs. Eine Evaluierung am Beispiel objektorientierter Analysemethoden. Shaker. Herzogenrath, Germany, 1996.

[SuWa01] Subramani, M.; Walden, E.: The Impact of E-Commerce Announcements on the Market Value of Firms. Information Systems Research 12(2), 2001: S. 135-154.

[Tam98] Tam, K. Y.: The Impact of Information Technology Investments on Firm Performance and Evaluation: Evidence from Newly Industrialized Economies. Information Systems Research 9(1), 1998: S. 85-98. 
[ToBe99] Todd, P.; Benbasat, I.: Evaluating the Impact of DSS, Cognitive Effort, and Incentives on Strategy Selection. Information Systems Research 10(4), 1999: S. 356-374.

[Vass00] Vassiliadis, P.: Gulliver in the land of data warehousing: practical experiences and observations of a researcher. In: Proceedings of the International Workshop on Design and Management of Data Warehouses (DMDW'2000), Stockholm, Sweden, 2000, S. 12(1) - 12(16).

[VaSe99] Vassiliadis, P.; Sellis, T.: A Survey of Logical Models for OLAP Databases. Sigmod Record 28(4), 1999: S. 64-69.

[Venk94] Venkatraman, N.: IT-Enabled Business Transformation: From Automation to Business Scope Redefinition. Sloan Management Review, 1994: S. 73-87.

[Wido95] Widom, J.: Research problems in data warehousing. In: Proceedings of the International Conference on Information and Knowledge Management, New York, NY, 1995.

[WiWa01] Wixom, B. H.; Watson, H. J.: An Empirical Investigation of the Factors Affecting Data Warehousing Success. MIS Quarterly 25(1), 2001: S. 17-41. 


\section{APPENDIX}

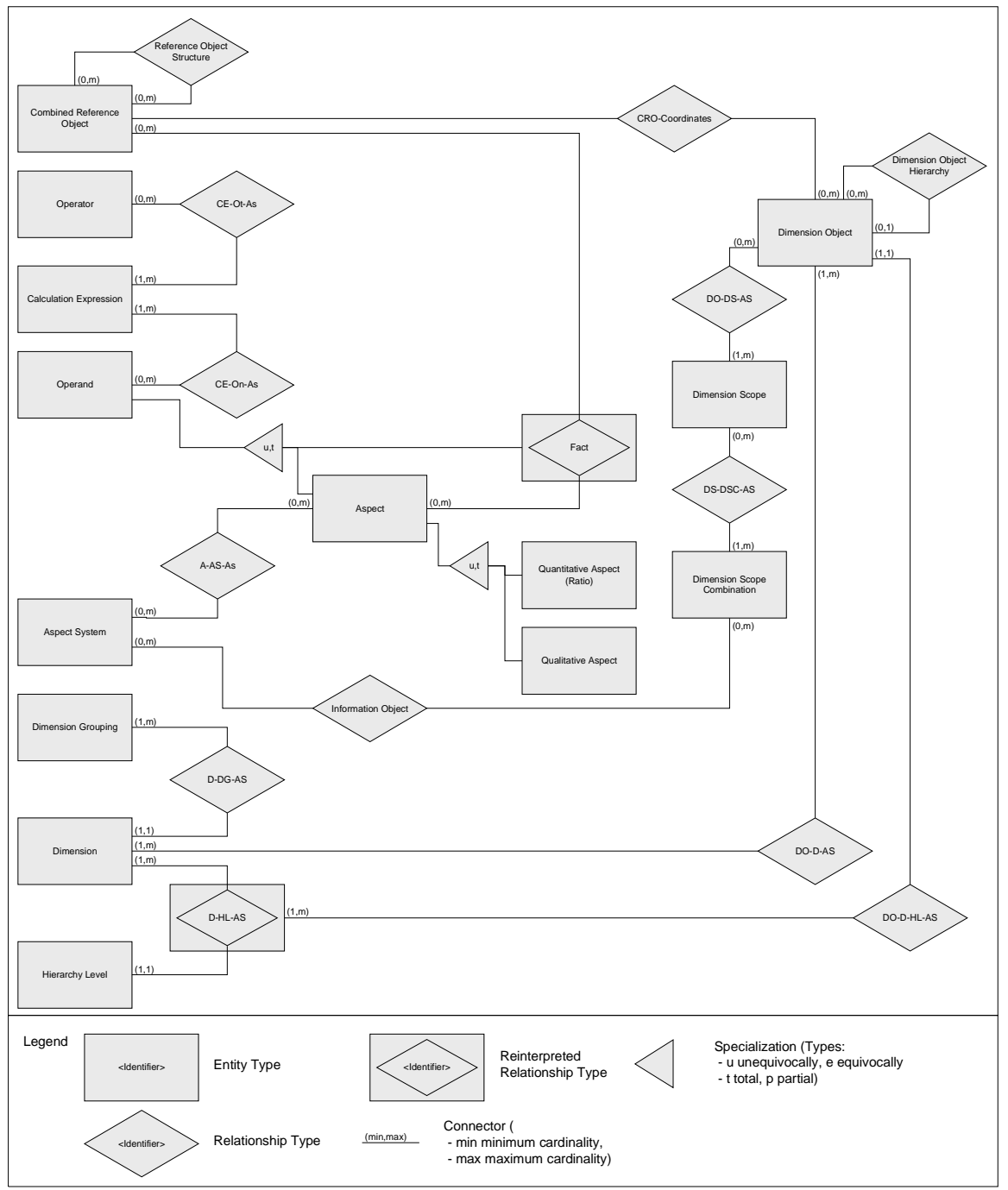

Appendix A: Excerpt of the Meta Model of Management Information Systems (compare to [Holt03]) 